\title{
Meningococcal disease: has the battle been won?
}

\author{
Beverley C Millar, ${ }_{1}^{1}$ P J A Moore, ${ }^{2}$ J E Moore ${ }^{1,2}$
}

- Additional material is published online only. To view please visit the journal online (http://dx.doi.org/10.1136/ jramc-2016-000695).

${ }^{1}$ Northern Ireland Public Health Laboratory, Department of Bacteriology, Belfast City Hospital, Belfast, UK ${ }^{2} \mathrm{~S}$ chool of Medicine, Dentistry and Biomedical Sciences, Queen's University Belfast, Belfast, UK

\section{Correspondence to} Dr Beverley C Millar, Northern Ireland Public Health Laboratory, Department of Bacteriology, Belfast City Hospital, Belfast BT9 7AD, UK:

bcmillar@niphl.dnet.co.uk

Received 27 July 2016 Revised 25 October 2016 Accepted 27 October 2016 Published Online First 29 December 2016

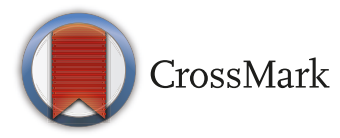

To cite: Millar $B C$ Moore PJA, Moore JE. J R Army Med Corps 2017; 163:235-241.

\section{ABSTRACT}

Meningococcal disease is a worldwide life-threatening infection associated in many cases with debilitating long-term sequelae, both within the military and civilian populations. Military recruits are at a higher risk of acquiring this infection due to numerous factors, such as young recruits in the age group 18-25 years, high carriage rates of meningococci, communal and crowed living quarters and global deployment or training in regions with different meningococcal serogroup epidemiology. Although these increased risk factors among young recruits remain, the increased incidence of disease is now historic. Numerous outbreaks have been reported among military personnel, however although the incidence of the disease continues to decrease, there are still sporadic cases. The non-specific symptoms, sudden onset and rapid progression of the infection results in a limited time frame to both diagnose and successfully treat the patient. Many developments have been made in relation to the microbiological diagnosis of the disease, particularly in the era of molecular diagnostics, which have the potential to diagnose the infection more quickly. Developments in vaccinology, and in particular with relation to biotechnology and reverse vaccinology, have led to the availability of new meningococcal vaccines, further enabling disease prevention. This paper outlines the history of meningococcal disease in relation to the military and highlights the new developments in both diagnostics and vaccination, which have the potential to diagnose, treat and control meningococcal disease in a more efficient manner.

\section{HISTORICAL INTRODUCTION}

Meningococcal disease primarily presents as meningitis and/or septicaemia (Box 1) and throughout history, has been a serious and life-threatening health issue in the military, more so than in the civilian population. Large epidemics occurred during the two World Wars, in the UK, Germany, France and the USA. ${ }^{1}$

The clinical and epidemiological accounts of the disease, however, were realised much earlier in the 19th century, first in Europe and North America in 1805 and 1806, respectively and later in Africa in $1905 .^{2}{ }^{3}$ The high incidence of meningococcal disease in the US military during World War I was 150/100 000 person-years and during World War II was $80 / 100000$ person-years. ${ }^{4}$ Such was the extent of meningococcal infection on morbidity and mortality that, from 1932 until the end of World War II, Japan included Neisseria meningitidis in their biological warfare programme, which included the experimental inoculation of prisoners from Korea, China, Mongolia, Russia, USA, UK and Australia. ${ }^{5}$ More recently, the number of cases of meningococcal disease in both the military and civilian
Key messages

Meningococcal disease both within the military and civilian populations has dramatically decreased, yet sporadic cases and clusters of cases still exist.

- Young military recruits from diverse geographical areas congregating in confined conditions, share different meningococcal strains, which may correlate with the new acquisition of a different meningococcus strain, in some cases.

- Immunisation of new recruits is important at commencement of their training, since this is the time they are at highest risk.

- The epidemiology of meningococcal disease has constantly been changing.

- Molecular characterisation and continual monitoring of strains circulating globally enables early detection of potential new outbreak or cluster strains and directs vaccination policy.

- All military personnel should be offered vaccines targeting the most common serogroups prevalent in the geographical regions to which they are deployed.

populations has decreased significantly, as noted in 2006-2013, where there were $0.27 / 100000$ person-years in the military, compared with 0.238 / 100000 person-years in the age-matched US civilian population during 2006-2012.6 So, has this life-threatening infection been defeated or have we been lulled into complacency?

Major General Priest, Consulting Physician British Expeditionary Force (France and Western Command (UK)), described his observations of meningococcal infections in the Army during an outbreak from September 1939 to May 1940. He recorded observations and formed conclusions about the nasopharyngeal carriage of meningococci, as well as the spread of the infection among military personnel in overcrowded, communal areas. He reported that the initial symptoms were difficult to accurately accredit to meningococcal disease and highlighted the subsequent sequalae associated with this infection. All of these observations are still only too notable today. ${ }^{7}$ At a time when antibiotics were in their infancy, Priest recorded the successful treatment of patients with penicillin and sulfonamides and subsequently, penicillin alone. He concurred with suggestions by Colonel Henry M Thomas Jr. Consultant, Fourth Service Command, US Army, that 'if all patients could be diagnosed and treated at the onset of the 
Box 1 Clinical manifestations of meningococcal infection

Common
Meningitis and/or
Less common
Pneumonia
Septic arthritis
Otitis media
- Epiglottitis
Pericarditis
- Conjunctivitis
- Urethritis

first symptom it is my firm belief that the mortality would be reduced to zero'; a viewpoint which is still held today. At that time, both the prophylactic value of the sulfonamide, sulfadiazine, in the control of meningococcal meningitis and sulfonamide resistance were realised. ${ }^{8}$

One hundred years later, our war with meningococcal disease continues, although several victories have been won against the infection. This paper outlines the historical significance of meningococcal disease and reviews the literature which has been published to date with specific reference to military personnel and details new developments in diagnostics and vaccination, as well as highlighting key guidelines which exist for the diagnosis and management of meningococcal meningitis and septicaemia.

\section{METHODS OF LITERATURE RETRIEVAL}

Numerous peer-reviewed articles have been published in relation to the epidemiology, carriage, clinical observations, cases, outbreaks, treatment and vaccination policies and their effectiveness, in relation to military personnel. A search for these articles published between 1914 and June 2016 was performed using PubMed and the ISI Web of Science. The search terms used were inclusive to the nature of the content material and included the title terms: 'meningococcal', 'meningitidis', 'army', 'armed forces', 'military', 'navy', 'naval', 'air force' and 'soldiers', including permutations and combinations of these search terms. Only articles written in the English language were retrieved. This search yielded 56 articles and an additional 23 articles were retrieved following further analysis of these core articles. A total of 63 references were included in the main review, as well as 64 references, which were included in online supplementary materials.

\section{THE MICROBIOLOGY OF MENINGOCOCCI}

The first description of meningococcal disease was in 1805 and the causative agent was cultivated and named 'Diplococcus meningitidis intracellularis', approximately 80 years later. ${ }^{9}$ During an epidemic among troops in training in 1915, Lt Col MH Gordon, CMG, Royal Army Medical Corps fully identified the microbiological details of the causative meningococcus, which were subsequently published in the J R Army Med Corps. ${ }^{10} \mathrm{He}$ recognised that there were different 'kinds' of Gram-negative meningococci which he wished 'to sort' by agglutination reactions with rabbit serum. In conjunction with his colleagues, he recognised that there were four main types or pathogenic members (I, II, III and IV) of the meningococci group which were identified with different frequencies, but acknowledged that there may be more. ${ }^{10}$ This was the foundation stone in the classification of $N$. meningitidis, which was subsequently modified by the Nomenclature Committee of the International Association of Microbiologists in 1950, with further serogroups being identified in the 1980s. ${ }^{11}$

It is now known that the Gram-negative proteobacterium, $N$. meningitidis has 12 serogroups characterised by their polysaccharide capsule, which is the organism's principal virulence factor, however six serogroups, namely $\mathrm{A}, \mathrm{B}, \mathrm{C}, \mathrm{W}, \mathrm{X}$ and $\mathrm{Y}$ account for most cases of meningococcal disease worldwide, with different seroprevalance (Figure 1 and online supplementary Figure S1). ${ }^{12}$ Meningococci are further classified into type and subtype on the basis of their outer membrane proteins, porins (porB and porA, respectively). ${ }^{13}$ Molecular methods, such as multilocus sequence typing are used in the classification of meningococci and with increasing availability and reducing costs, whole genome sequencing, is currently providing further insights into the characterisation and accurate typing of isolates. ${ }^{14}$

\section{EPIDEMIOLOGY}

Epidemics during World War I and World War II are believed to have been the result of serogroup A infection and following this period disease levels declined, particularly those infections due to this capsular group, although serogroup A has been primarily endemic in the African meningitis belt and in the Middle East. ${ }^{3}$

There have been several hyperendemic periods during the past 45 years, namely in 1972-1975, associated with capsular serogroup B serotype 2 a strain, then in 1985, associated with a hypervirulent ST32, B15:P1.16 strain and a further hyperendemic period in 1995-1996, associated with an increased proportion of disease due to ST11 capsular group C serotype 2a infection. The occurrence of the latter promoted the introduction of a MenC vaccination programme in the UK from November 1999, which resulted in a significant decrease in cases due to this serogroup. ${ }^{15}$

Of global concern is the increasing incidence of meningococci belonging to the ST-11 clonal complex (cc11), which are hyperinvasive and may express serogroups $\mathrm{B}, \mathrm{C}, \mathrm{W}$ or $\mathrm{Y}$. This complex is associated with high rates of morbidity and mortality and has the potential to cause outbreaks and epidemics, such as the serogroup B and C outbreaks in the US military in the 1960s, the Hajj-associated outbreak of MenW in 2000 and the subsequent MenW epidemics in the meningitis belt of sub-Saharan Africa, since $2001 .{ }^{16}$

More recently, outbreaks of MenC:cc11 have been reported in North America, Germany and France, among men who have sex with men, which has prompted vaccination of this population. ${ }^{17-19}$ Increasing endemic MenW:cc11 disease, with its case fatality rates approaching $28 \%$, has been of concern in both South Africa and Brazil since 2003 and subsequently in several other South American countries. Since 2009, there has also been an increase in cases of MenW:cc11 in the UK, which may suggest a new hyperendemic period. Although the UK MenW: cc11 strain is distant from the 2000 Hajj strain, it is similar to the South American and closely related to an endemic South African strain. ${ }^{16}$

\section{RISK FACTORS FOR MENINGOCOCCAL DISEASE}

Risk factors for meningococcal disease (or cerebrospinal fever as it was originally known) were highlighted by Capt JA Glover RAMC in $1918 .^{20} \mathrm{He}$ suggested that outbreaks were associated with aetiological factors, including the winter season, severe 


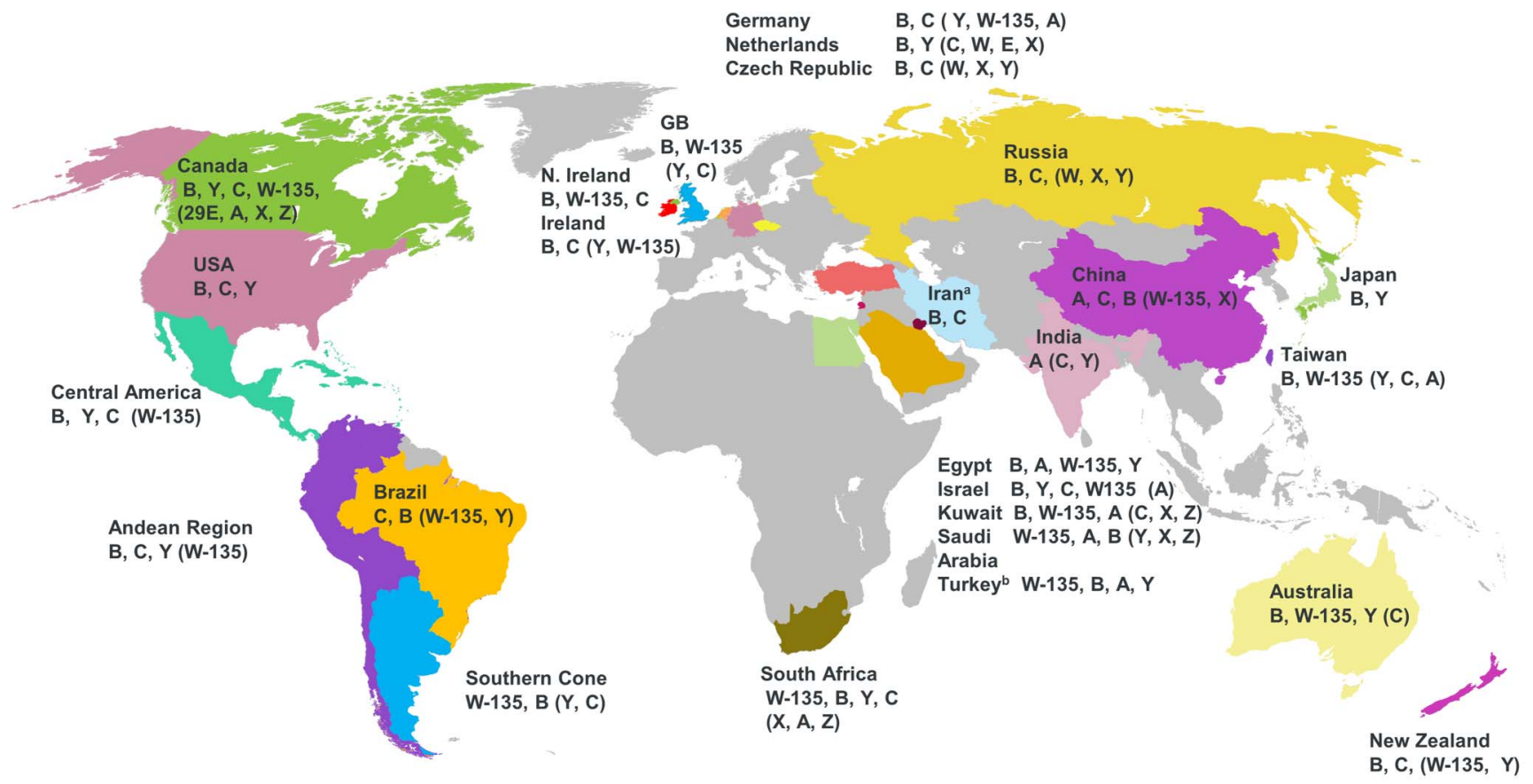

* listed in order of prevalence

anot listed in order of prevalence

bas observed in children

Figure 1 Global meningococcal serogroup distribution.

weather, antecedent epidemics of influenza, temporary lowering of resistance due to strenuous training, overcrowding and high carrier rate of epidemic strains, all of which continue to be recognised today. ${ }^{20}$ Glover introduced what he called 'Spacing Out', which required at least two and a half feet between each bed situated in recruit living quarters, particularly during the first 3 months of service and he subsequently observed a reduction in carriage rate from $22 \%-28 \%$ to $2 \%-4.5 \% .^{20}$

Crowded and communal living poses a major risk for the transmission of meningococci among military recruits due to the high carriage rate, ranging from $10 \%$ to $65 \%$ (see online supplementary Table S1). The duration and rate of carriage varies but in general, there is an increase in carriage throughout the initial months of basic training (see online supplementary Table S1). Colonisation of meningococci in the oropharynx, in the majority of cases induces an antibody response within a few weeks after acquisition, resulting in asymptomatic carriers. However, a high carrier rate increases the risk of transmission of strains to individuals living in large communal accommodation and working in close proximity, some of which may be potentially invasive, ${ }^{21}$ as was the case in a Danish military recruit, who acquired a pathogenic strain of serogroup B meningococci from healthy carriers in his living accommodation. ${ }^{22}$ As carriage rates and cases of meningococcal disease are primarily independent of each other, chemoprophylaxis to reduce carriage rates should only be advocated in a suspected outbreak scenario.

Deployment to geographical areas which have different endemic serogroups of $N$. meningitidis, to that of home countries, is an additional risk factor as military personnel may potentially acquire a serogroup for which they are immunologically naïve. A further risk factor relates to age, in that military recruits are generally in the age group 19-25 years, which is the age group at second greatest risk for invasive disease, after those in infancy. Additional suggested risk factors include smoking, passive smoking and a recent history of upper respiratory infection. ${ }^{23}$

\section{MENINGOCOCCAL INFECTION IN THE MILITARY}

During the 1800s and early to mid-1900s, numerous large-scale meningococcal outbreaks were identified worldwide both within the civilian and military populations. ${ }^{9}{ }^{24}$ Over the last 50 years, there have been a number of outbreaks or clusters of meningococcal disease reported among the military, however, these have been on a much smaller scale (see online supplementary Table S2).

The rate of meningococcal disease has declined steadily since the 1960s, with most notable declines following the introduction of vaccination. Between the period 1964 and 1966, the most prevalent serogroup was $\mathrm{B}$, with one report indicating a prevalence of $92.6 \%$ and serogroup $\mathrm{C}$ only accounting for $9.4 \% ;{ }^{25} 261967$ saw the start of a changing epidemiology with serogroup B accounting for $35.8 \%$ and serogroup C $54.7 \%$ and by 1969 , serogroup B accounted for $11.7 \%$ of cases. The sharp decrease in rate of meningococcal disease due to serogroup $B$ occurred even in the absence of intervention by vaccination. An increase in cases due to serogroup C continued in the years 1968 and 1969 (87.4\%), however by 1973, due to infection prevention measures and vaccination, only five cases of meningococcal disease were noted in the US military. ${ }^{4}$ The number of yearly cases have decreased significantly since the mid-1970s, there have, however, been increased reports of cases due to serogroups W-135 and Y, again promoting a change in vaccination programmes. $^{4}$

During the period 1971-2010, it was observed that the overall incidence among the US military was not significantly different from the civilian population, namely 0.38 vs 0.26 
cases per 100000 person-years, respectively, however, the peak disease incidence in military personnel occurred among the age group 17-19 years and this incidence was significantly higher than in their counterparts in the civilian population (2.34 vs 0.62 cases per 100000 person-years, respectively). ${ }^{6}$ During these 40 years, there were only 26 cases reported, of which 5 were fatal. The serogroup distribution indicated a predominance of serogroup Y (10 cases), with the remaining known serogroups being $\mathrm{C}$ ( 7 cases) and B (6 cases). Fifteen cases (57.7\%) were classified as vaccine failures, that is, meningococcal disease occurred during 1-48 months postvaccination, $85 \%$ of which had been vaccinated $<1$ year previously and of which three died. ${ }^{6}$ Subsequently, the incidence of meningococcal disease in the US military decreased further to 0.17 cases per 100000 person-years, with only one case each in 2011 (serogroup Y) and 2012 (serogroup B) and three cases were recorded in 2013 (1 each of serogroups B, C and Y). ${ }^{27} 28$

Recently, published global military case studies highlight that although there has been a dramatic reduction of reported meningococcal disease, as has been the case in the civilian population, there are isolated sporadic cases, which still have a high incidence of morbidity and mortality (see online supplementary Table S3). Some of these cases relate to individuals who had been vaccinated prior to, or on, admission as a military recruit. Additionally, although new recruits are at increased risk, meningococcal disease can also occur in experienced military personnel in active service both at home and during deployment.

\section{DIAGNOSIS AND TREATMENT}

It is of utmost importance that a quick, confirmed diagnosis is achieved, so that appropriate management of either meningitis and/or meningococcal sepsis can be commenced. Due to both the low frequency with which meningococcal infection presents and the non-specific nature of early symptoms, the infection may be difficult to accurately diagnose in a timely manner (Table 1).

Recently, there have been two seminal publications on the diagnosis, treatment, prevention and control of meningococcal disease, namely those prepared by the 'Global Meningococcal Initiative ${ }^{29}$ and 'The UK Joint Specialist Societies'. ${ }^{30}$ These comprehensive guidelines are excellent reference resources, the key points of which have been summarised in online supplementary Table S4.

Microbiological examination is fundamental in the confirmation of meningococcal disease and early reports of the methods of sampling and culturing of nasopharyngeal swabs, cerebral spinal fluid (CSF) and blood culture were documented by Capt W James Wilson, RAMC, relating to observations in the Belfast Military district during 1915-November 1916. He noted the

Table 1 Symptoms of meningococcal infection

\begin{tabular}{ll}
\hline Fever & Cold hands and feet \\
Vomiting & Diarrhoea \\
Irritability & Confusion \\
Lethargy/drowsiness & Difficult to wake \\
Photophobia & Severe headache \\
Muscle pains & Stiff/painful neck \\
Convulsions/seizures & Pale blotchy skin \\
Rash & Thirst \\
Coryza & Sore throat \\
Cough & Hypotension (occurs late in septic shock) \\
\hline
\end{tabular}

difficulties with the recognition of organisms on culture plates and developed novel methods to acquire a nasopharyngeal swab, as well as a supplemented blood broth to isolate meningococci from both CSF and blood culture. ${ }^{31}$ Indeed, many of these concepts are used in classical meningococcal diagnostic microbiology today.

As N. meningitidis is a hazard category group 2 organism, query samples and cultures should be processed under appropriate level 2 containment. Additionally, it is recommended that laboratory staff are vaccinated with both the quadrivalent conjugate vaccine for serogroups ACWY (MenACWY) vaccine and for serogroup B (MenB). ${ }^{15}{ }^{32}$ An early case of possible laboratory-acquired meningococcal disease, by bacteriologist, Lt Sydney Domville Rowland during World War I in Étaples, France highlights the importance of such health and safety measures. $^{33}$

Novel molecular assays have been developed and although not routine, may be of particular use in cases which are culture negative. Detection of meningococcal DNA in CSF using specific gene loci or universal gene targets, namely the 16S rRNA gene can result in quicker detection than that of conventional culture and identification. ${ }^{34}$ More recently, molecular methods using loop-mediated isothermal amplification have been developed to detect meningococci. ${ }^{35}$ This test is faster than conventional PCR, has an enhanced sensitivity and is easy to use and evaluate, as it is based on a visual colorimetric inspection. It has proven useful in near-patient testing of non-invasive respiratory specimens from children, where it has been reported diagnostically accurate and specific when compared with culture and PCR of blood and CSF specimens. ${ }^{36}$

\section{PREVENTION AND CONTROL}

Infection prevention and control is of utmost importance, particularly among military recruits as is the case with other at-risk populations, for example, children, adolescents and laboratory staff. The US Advisory Committee on Immunization Practices (ACIP), ${ }^{37} 38$ the Department of Health, $\mathrm{UK}^{15}$ and other countries have published vaccination policies within these at-risk groups, particularly the military. ${ }^{39}$ Apart from the logistical layout of the trainee living accommodation, vaccination is key to prevention. Control in outbreak situations may be by means of either or both vaccination and chemoprophylaxis (see online supplementary Table S4).

\section{CHEMOPROPHYLAXIS}

It has been widely accepted that chemoprophylaxis reduces rates of carriage of meningococci in the military population; however, this approach must be restricted to outbreak or close contacts, following confirmation of a case. It must be determined that the causative strain is sensitive to the antibiotic of choice, as highlighted by a study on the effect of rifampin on the carriage in military trainees, which reported a reduction in carriage from $65.1 \%$ to $10.1 \% 4$ days after treatment, followed by a rapid increase in carriage indicating the emergence of rifampin-resistant strains. ${ }^{40}$ Ciprofloxacin has also been shown to be effective in eradicating pharyngeal colonisation and is the preferred choice for chemoprophylaxis in the UK Joint Infection guidelines. ${ }^{30}{ }^{41}$ It has been reported, however, that a single prophylactic dose of ciprofloxacin, failed to eradicate meningococcal carriage in a small number of military recruits. ${ }^{42}$

\section{VACCINATION}

The military has lead in the development of meningococcal vaccines with early attempts including a dried preparation of 
several strains of meningococcus and treatment of patients with intraspinal injections of serum. ${ }^{31}$ It was not until 1968 that researchers at the Walter Reed Army Institute of Research, Washington, DC developed the first successful polysaccharide meningococcal vaccine against serogroup $\mathrm{C}$ strains, which was subsequently introduced among the US military trainees during 1969-1971. ${ }^{43}$ Subsequent field trials of this vaccine reported a reduction in serogroup C-related meningococcal disease rate, with $89.5 \%$ efficacy. ${ }^{44}$ Carriage studies observed a reduction in acquisition of serogroup $C$ in vaccinated subjects, however, in some cases the carrier rate of other serogroups was higher. ${ }^{46}$ This advocated the requirement for a polyvalent vaccine, with particular emphasis on serogroups A, B and C. ${ }^{45}$

A bivalent vaccine for serogroups $\mathrm{A}$ and $\mathrm{C}$ and a quadrivalent polysaccharide vaccine (MPSV-4) for serogroups A, C, W-135 and Y, followed in 1978 and 1982, respectively. ${ }^{4}$ More recently, a quadrivalent meningococcal conjugate vaccine, MCV-4 was recommended, in 2005, and replaced MPSV-4 over the period 2006-2008 ${ }^{27}$ MCV-4 is currently recommended for military recruits, at risk groups and for adolescents in the USA and since 2015 , adolescents and first-year university students in the UK. ${ }^{47} 48$

The development of a MenB vaccine has been difficult, due to the heterogeneity of the dominant protein PorA and the fact that the polysaccharide capsule of serogroup B contains a derivative of polysialic acid which is found in many human tissues, such as in the central nervous system, thus leading to a poor immune response and the possibility of autoantibody production. ${ }^{49}$ Reverse vaccinology, which uses the complete genome sequence to search or 'mine', in silico, for specific genes that are predicted to encode for proteins that are either exposed on the pathogen's surface or secreted and as such will be accessible to antibodies, has been used to develop two new MenB vaccines, namely MenB-factor $\mathrm{H}$ binding protein ( $\mathrm{FHbp}$ ) (Trumenba, Pfizer) and 4CMenB (Bexsero, GSK). The 4CMenB vaccine consists of three recombinant proteins: (i) Neisserial adhesin A, a meningococcal protein important with respect to adhesion and invasion of epithelial cells, (ii) FHbp, a fusion protein, which binds human factor $\mathrm{H}$ which enables evasion of the human immune response by downregulation of complement-mediated killing and (iii) Neisseria heparin binding antigen, a fusion protein, which is involved in increased resistance to host clearance. This vaccine also contains outer membrane vesicles containing outer membrane protein PorA serosubtype P1.4, which has a dual role as both antigens and adjuvant. ${ }^{50}$ The MenB-FHbp vaccine consists of two purified recombinant $\mathrm{FHbp}$ antigens, one from each FHbp subfamily (A and B). ${ }^{51}$

Both MenB vaccines have been licensed by the Food and Drug Administration and approved for use in persons aged 1025 years. The ACIP has recommended the use of MenB vaccines among certain groups of persons aged $\geq 10$ years, who are at increased risk for serogroup B meningococcal disease but not in military recruits. ${ }^{38}$ Of significance, the UK is the first European country to introduce routine MenB vaccination of babies and infants. $^{50}$

Vaccination programmes with the meningococcal A conjugate vaccine (MenAfriVac) has dramatically reduced the number of cases due to N. meningitidis $\mathrm{A}$ in epidemic areas in the meningitis belt, however since 2001, an emergence of serogroup X has promoted the necessity for further research into the development of an affordable and temperature stable conjugate MenACWYX vaccine indicating that we cannot be complacent, and must be aware of the changing epidemiology of meningococcal infection. ${ }^{52} 53$
Vaccination may also be used as a control measure during sporadic and outbreak cases. An early example of the role of vaccination in control was observed in the mid-1980s, when a polysaccharide vaccine was used for, the first time, during an outbreak in Royal Air Force recruits due to N. meningitidis group C type PI, $2 .{ }^{54}$ Recently, MenB conjugate vaccines have been successfully used in the control of outbreaks at universities. ${ }^{5556}$ The largest mass vaccination against serogroup B, was in 2014, among individuals aged 2 months to 20 years, in the Saguenay-Lac-St-Jean region of Quebec, in order to control the spread of the meningococcal serogroup B disease, which had an incidence rate more than 10 times higher than the rest of Canada during 2006-2012. The results of this vaccination campaign showed a high level of direct protection during the first year following administration of the first vaccine dose; however, it failed to provide an indirect herd protection in adults. ${ }^{57}$

Following vaccination of military personnel, a reduction in outbreaks of meningococcal disease and incidence has been noted, ${ }^{58-61}$ however in the British Armed Forces during 19891997, although such a reduction was reported in trained soldiers, this was not the case in recruits. ${ }^{62}$ The current vaccination policy of military recruits within the USA and the UK is with a MenACWY conjugate vaccine, however this may not be the policy worldwide.

Even if recruits are vaccinated against any of the capsular groups, it must be stressed that vaccination does not cover all serogroups of meningococci, nor all organisms which cause meningitis. It is therefore important that recruits are educated with respect to the signs and symptoms of meningococcal disease, particularly as they participate in exhausting training regimes that may result in a masking of symptoms which may be confused with fatigue, food poisoning or other illnesses. It must also be realised that persistence of antibody responses following vaccination may decrease with time and this waning effect must be considered when deciding when to implement booster doses. ${ }^{47}$

\section{REFLECTION}

Field Marshal Frederick Sleigh Roberts, 1st Earl Roberts of Kandahar, Pretoria and Waterford (1832-1914) was one of most successful military commanders of the 19th century. His disability of blindness in one eye, resulting from childhood meningitis, did not hinder him from leading his men in numerous notable battles, including the Second Boer War, 1900. On his return to England, he became Commander-in-Chief of the British Army and advocated the introduction of conscription, in order to prepare for a great European war. During World War I, on 14 November 1914, aged 82, Roberts died of pneumonia, while visiting Indian troops at St Omer, France. Today, a statue of Lord Roberts sitting on his charger, Vonolel, who carried him 50000 miles on his campaigns throughout India and Afghanistan, stands in Horse Guards Parade, London (Figure 2), to remind us of this remarkable man of great military standing, and as a testament to the fact of what we can achieve by overcoming the devastating illness of meningococcal disease, provided we have a well-prepared plan of attack, enabling us to conquer and realise that following victory, on the horizon there is always another battle to fight. ${ }^{63}$

\section{CONCLUSION}

In conclusion, meningococcal disease both within the military and civilian populations has dramatically decreased. The epidemics that were observed during the two World Wars and the outbreaks in the 1960s and 1970s are no longer, however 
Figure 2 Statue of Field Marshal Lord Roberts and his charger Vonolel, Horse Guards Parade, London.

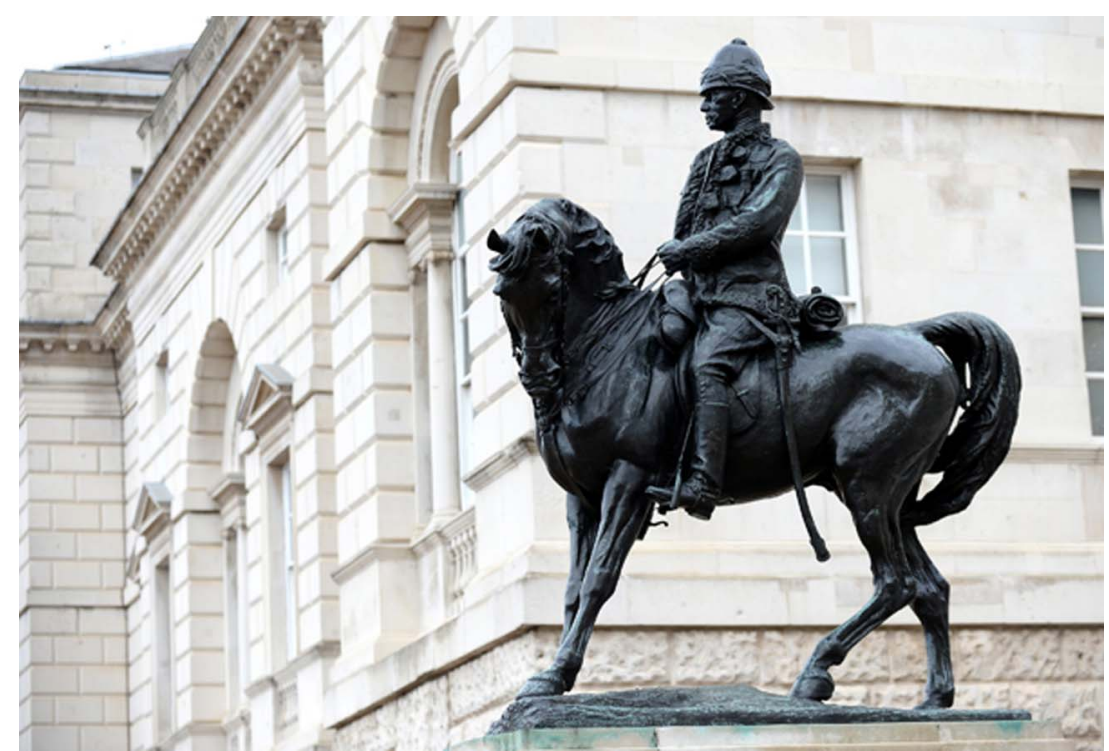

sporadic cases and clusters of cases still exist. It is fundamental to a successful outcome that such cases are diagnosed quickly, accurately and treated with the appropriate medication. All close contact individuals must be identified quickly and offered appropriate chemoprophylaxis and vaccination if appropriate. There is clear epidemiological evidence, from military and civilian populations, that the increased risk is primarily associated with young adults from diverse geographical areas congregating in confined conditions, who then share different meningococcal strains, which may correlate to new acquisition of a different meningococcus strain, in some cases. This is the rationale for advocating the immunisation of new recruits at commencement of their training, since this is the time they are at highest risk. Additionally, all military personnel should be offered vaccines targeting the most common serogroups prevalent in the geographical regions to which they are deployed. The epidemiology of meningococcal disease has constantly been changing. Molecular characterisation methodologies and continual monitoring of strains circulating globally will enable the early detection of potential new outbreak or cluster strains, which will further direct vaccination policy, both within military and civilian populations.

Contributors All authors have been involved in the conception, literature search and design of the manuscript.

Competing interests None declared.

Provenance and peer review Not commissioned; externally peer reviewed.

\section{REFERENCES}

1 Priest R, Jr. Meningococcal infections in the army 1939-1945, with 30 selected illustrative cases. J R Army Med Corps 1947;89:1-28.

2 Phair JJ. (1958) Meningococcal meningitis. In: Coates JB, Hoff C, Hoff PM, eds. Preventive medicine in WWII, volume IV, communicable diseases, transmitted chiefly through respiratory and alimentary tracts. Washington DC. http://history.amedd. army.mil/booksdocs/wwii/PM4/CH11.Meningitis.htm (accessed 25 Jul 2016).

3 Abio A, Neal KR, Beck CR. An epidemiological review of changes in meningococcal biology during the last 100 years. Pathog Glob Health 2013;107:373-80.

4 Brundage JF, Ryan MA, Feighner $\mathrm{BH}$, et al. Meningococcal disease among United States military service members in relation to routine uses of vaccines with different serogroup-specific components, 1964-1998. Clin Infect Dis 2002;35:1376-81.

5 Riedel S. Biological warfare and bioterrorism: a historical review. Proc (Bayl Univ Med Cent) 2004;17:400-6.

6 Broderick MP, Faix DJ, Hansen CJ, et al. Trends in meningococcal disease in the United States military, 1971-2010. Emerging Infect Dis 2012;18:1430-7.
7 Thomas HM, Jr. Meningococcal meningitis and septicaemia: report of outbreak in Fourth Service Command during winter and spring of 1942-1943. JAMA 1943;123:264-72.

8 Kuhns DM, Feldman HA. Laboratory methods used in determining the value of sulfadiazine as a mass prophylactic against meningococcic infections. Am J Public Health Nations Health 1943;33:1461-5.

9 Leimkugel J, Racloz V, Jacintho da Silva $\mathrm{L}$, et al. Global review of meningococcal disease. A shifting etiology. J Bacteriol Res 2009;1:6-18.

10 Gordon $\mathrm{MH}$. Identification of the meningococcus. J R Army Med Corps 1918;30:1-22.

11 Harrison $\mathrm{OB}$, Claus $\mathrm{H}$, Jiang $\mathrm{Y}$, et al. Description and nomenclature of Neisseria meningitidis capsule locus. Emerging Infect Dis 2013;19:566-73.

12 CDC. Laboratory Methods for the Diagnosis of Meningitis. CHAPTER 7 Identification and Characterization of Neisseria meningitidis. http://www.cdc. gov/meningitis/lab-manual/chpt07-id-characterization-nm.html (accessed $25 \mathrm{Jul}$ 2016).

13 Jolley KA, Brehony C, Maiden MC. Molecular typing of meningococci: recommendations for target choice and nomenclature. FEMS Microbiol Rev 2007;31:89-96.

14 Jones $\mathrm{CH}$, Mohamed N, Rojas E, et al. Comparison of phenotypic and genotypic approaches to capsule typing of Neisseria meningitidis by use of invasive and carriage isolate collections. J Clin Microbiol 2016;54:25-34.

15 PHL England 2015. The green book. Meningococcal, Chapter 22. 2015. https://www.gov.uk/government/uploads/system/uploads/attachment_data/file/ 462629/2904512 Green_Book_Chapter_22 v6_OW.PDF (accessed 25 Jul 2016).

16 Lucidarme J, Hill DM, Bratcher HB, et al. Genomic resolution of an aggressive, widespread, diverse and expanding meningococcal serogroup $B, C$ and $W$ lineage. J Infect 2015;71:544-52.

17 Simon MS, Weiss D, Geevarughese A, et al. Cost-effectiveness of meningococcal vaccination among men who have sex with men in New York city. J Acquir Immune Defic Syndr 2016;71:146-54

18 Aubert L, Taha M, Boo N, et al. Serogroup C invasive meningococcal disease among men who have sex with men and in gay-oriented social venues in the Paris region: July 2013 to December 2014. Euro Surveill 2015;20: pii:21016

19 Marcus U, Vogel U, Schubert A, et al. A cluster of invasive meningococcal disease in young men who have sex with men in Berlin, October 2012 to May 2013. Euro Surveill 2013;18:pii:20523.

20 Glover JA. "Spacing-out" in the prevention of military epidemics of cerebro-spinal fever. BMJ 1918;2:509-12.

21 Caugant DA, Høiby EA, Rosenqvist E, et al. Transmission of Neisseria meningitidis among asymptomatic military recruits and antibody analysis. Epidemiol Infect 1992;109:241-53.

22 Andersen J, Berthelsen L, Jensen BB, et al. Surveillance of cases of meningococcal disease associated with military recruits studied for meningococcal carriage. Scand J Infect Dis 2000;32:527-31.

23 BMJ Best Practice Meningococcal Disease. http://bestpractice.bmj.com/best-practice/ monograph/542.html (accessed 25 Jul 2016).

24 Sartwell PE, Smith WM. Epidemiological notes on meningococcal meningitis in the army. Am J Public Health Nations Health 1944;34:40-9. 
25 Wolf RE, Birbara CA. Meningococcal infections at an army training center. Am J Med 1968:44:243-55.

26 Artenstein MS, Schneider H, Tingley MD. Meningococcal infections. 1. Prevalence of serogroups causing disease in US Army personnel in 1964-70. Bull World Health Organ 1971;45:275-8.

27 Broderick MP. Surveillance snapshot: cases of service member meningococcal disease reported to the Naval Health Research Center Laboratory-based Meningococcal Disease Surveillance Program, 2006-2014. MSMR 2014;21:18.

28 Broderick MP, Phillips C, Faix D. Meningococcal disease in US military personnel before and after adoption of conjugate vaccine. Emerging Infect Dis 2015;21:377-9.

29 Vázquez JA, Taha MK, Findlow J, et al. Global Meningococcal Initiative: guidelines for diagnosis and confirmation of invasive meningococcal disease. Epidemiol Infect 2016;144:3052-7.

30 McGill F, Heyderman RS, Michael BD, et al. The UK joint specialist societies guideline on the diagnosis and management of acute meningitis and meningococcal sepsis in immunocompetent adults. J Infect 2016;72: 405-38.

31 Wilson WJ, Purce RB, Darling G. Certain points observed with regard to cerebrospinal fever in the Belfast Military District during 1915 and up to November 1916. BMJ 1916;2:900-4

32 Findlow J, Bai $\mathrm{X}$, Findlow $\mathrm{H}$, et al. Safety and immunogenicity of a four-component meningococcal group $B$ vaccine (4CMenB) and a quadrivalent meningococcal group ACWY conjugate vaccine administered concomitantly in healthy laboratory workers. Vaccine 2015;33:3322-30

33 Wever PC, Hodges AJ. The First World War years of Sydney Domville Rowland: an early case of possible laboratory-acquired meningococcal disease. J R Army Med Corps 2016:162:310-15.

34 Xu J, Millar BC, Moore JE, et al. Employment of broad-range 16S rRNA PCR to detect aetiological agents of infection from clinical specimens in patients with acute meningitis - rapid separation of 16S rRNA PCR amplicons without the need for cloning. J App/ Microbiol 2003;94:197-206.

35 Lee D, Kim EJ, Kilgore PE, et al. Clinical evaluation of a loop-mediated isothermal amplification (LAMP) assay for rapid detection of Neisseria meningitidis in cerebrospinal fluid. PLOS ONE 2015;10:e0122922.

36 Bourke TW, McKenna JP, Coyle PV, et al. Diagnostic accuracy of loop-mediated isothermal amplification as a near-patient test for meningococcal disease in children: an observational cohort study. Lancet Infect Dis 2015;15:552-8.

37 Cohn AC, MacNeil JR, Clark TA, et al. Prevention and control of meningococcal disease: recommendations of the Advisory Committee on Immunization Practices (ACIP). MMWR Recomm Rep 2013;62:1-28.

38 MacNeil JR, Rubin L, Folaranmi T, et al. Prevention and control of meningococca disease: recommendations of the Advisory Committee on Immunization Practices (ACIP). Use of Serogroup B Meningococcal Vaccines in Adolescents and Young Adults: Recommendations of the Advisory Committee on Immunization Practices, 2015. MMWR Morb Mortal Wkly Rep 2015;64:1171-6.

39 Lee SO. Commencement of the meningococcal vaccination for the Republic of Korea army. Infect Chemother 2013;45:113-15.

40 Beam WE Jr, Newberg NR, Devine LF, et al. The effect of rifampin on the nasopharyngeal carriage of Neisseria meningitidis in a military population. I Infect Dis 1971;124:39-46.

41 Renkonen OV, Sivonen A, Visakorpi R. Effect of ciprofloxacin on carrier rate of Neisseria meningitidis in army recruits in Finland. Antimicrob Agents Chemother 1987:31:962-3.

42 Kilic A, Jolley KA, Gul HC, et al. Genetic and antigenic characterization of Neisseria meningitidis strains from Turkish recruits in 2006. Intern Med 2008;47:1949-50
43 Gotschlich EC, Liu TY, Artenstein MS. Human immunity to the meningococcus: III. Preparation and immunochemical properties of the group $A$, group $B$, and group $C$ meningococcal polysaccharides. J Exp Med 1969;129:1349-65.

44 Artenstein MS, Gold R, Zimmerly JG, et al. Prevention of meningococcal disease by group C polysaccharide vaccine. N Engl J Med 1970;282:417-20.

45 Gold R, Artenstein MS. Meningococcal infections. 2. Field trial of group C meningococcal polysaccharide vaccine in 1969-70. Bull World Health Organ 1971:45:279-82.

46 Gotschlich EC, Goldschneider I, Artenstein MS. Human immunity to the meningococcus: $V$. The effect of immunization with meningococcal group $C$ polysaccharide on the carrier state. J Exp Med 1969;129:1385-95.

47 Patel M, Romero-Steiner S, Broderick MP, et al. Persistence of serogroup C antibody responses following quadrivalent meningococcal conjugate vaccination in United States military personnel. Vaccine 2014;32:3805-9.

48 Campbell $H$, Saliba V, Borrow $R$, et al. Targeted vaccination of teenagers following continued rapid endemic expansion of a single meningococcal group $\mathrm{W}$ clone (sequence type 11 clonal complex), United Kingdom 2015. Euro Surveill 2015;20: pii:21188.

49 Andrews SM, Pollard AJ. A vaccine against serogroup B Neisseria meningitidis: dealing with uncertainty. Lancet Infect Dis 2014;14:426-34.

50 Ladhani SN, Campbell H, Parikh SR, et al. The introduction of the meningococcal B (MenB) vaccine (Bexsero@) into The National infant immunisation programmenew challenges for public health. J Infect 2015;71:611-14.

51 Harrison LH. Vaccines for prevention of group B meningococcal disease: not your father's vaccines. Vaccine 2015;33:D32-8

52 Maïnassara HB, Paireau J, Idi I, et al. Response strategies against meningitis epidemics after elimination of serogroup A meningococci, Niger. Emerg Infect Dis 2015;21:1322-9.

53 Xie 0 , Pollard AJ, Mueller JE, et al. Emergence of serogroup X meningococcal disease in Africa: need for a vaccine. Vaccine 2013;31:2852-61.

54 Masterton RG, Youngs ER, Wardle JC, et al. Control of an outbreak of group C meningococcal meningitis with a polysaccharide vaccine. J Infect 1988;17:177-82.

55 McNamara LA, Shumate AM, Johnsen $P$, et al. First use of a serogroup B meningococcal vaccine in the US in response to a university outbreak. Pediatrics 2015;135:798-804.

56 Soeters HM, McNamara LA, Whaley $M$, et al. Serogroup B meningococcal disease outbreak and carriage evaluation at a college-Rhode Island, 2015. MMWR Morb Mortal Wkly Rep 2015;64:608-12.

57 de Wals P. Results of a mass immunisation campaign with 4-components serogroup b meningococcal vaccine (4CMenB) in Quebec, Canada. In: Proceedings of Meningitis \& Septicaemia in Children \& Adults 2015. London, UK: Royal Society of Medicine. MRF Conference December 2015. http://www.meningitis.org/ conference2015\#sthash.Ywj176IM.dpuf (accessed 25 Jul 2016).

58 Stroffolini T, Angelini L, Galanti I, et al. The effect of meningococcal group A and C polysaccharide vaccine on nasopharyngeal carrier state. Microbiologica 1990;13:225-9.

59 Biselli R, Fattorossi A, Matricardi PM, et al. Dramatic reduction of meningococcal meningitis among military recruits in Italy after introduction of specific vaccination. Vaccine 1993;11:578-81.

60 Mimouni $D$, Bar-Zeev $Y$, Huerta $M$, et al. Preventive effect of meningococcal vaccination in Israeli military recruits. Am J Infect Control 2010;38:56-8.

61 Mehrabi Tavana A, Ataee RA. Meningococcal meningitis control in Iran: five year comparative study 2000-2004. J Med Sci 2009;9:51-4.

62 Bergman BP, Hayton JC, Green AD. Effectiveness of the meningococcal vaccination programme for British Armed Forces recruits. Commun Dis Public Health 2000;3:298-9.

63 British Army. 2014. Drumhead Service held in memory of VC hero. 17 November 2014. http://www.army.mod.uk/news/26713.aspx (accessed 25 Jul 2016). 